\title{
A Novel Buck Boost Converter Feeded from Solar to Standalone System
}

\author{
Priyanka Kandregula, J Bhavani, T. Nireekshana
}

\begin{abstract}
For the present standalone system which the power taken from solar system and given to the off-grid loads are required number of stages of conversions of power thereby there is loss in reliability and efficiency of the system. To reduce the stages we have to either increase the rating of the battery or increase the number of solar cells in the system to increase the voltage level, but while increasing the rating of battery or solar cell it may cause the installation complications and it will be expensive. However, to satisfy the above disadvantages we are introducing a novel boost inverter that did not require any increase the voltage level in battery or increment of solar panels in the solar system. The system dependableness and potency area unit magnified. The brief analytical study of the system is performed. The efficiency of the system is validated by MATLAB simulation.
\end{abstract}

Keywords: Buck-Boost converter, DC-DC converter, Full bridge inverter, Maximum Power Point Tracking (MPPT), photovoltaic (PV), standalone system.

\section{INTRODUCTION}

The examination enthusiasm for sustainable power sources (res) has developed extensively as of late because of genuine concerns with respect to a rise in worldwide temperatures, change in environmental and lessening petroleum consumption utilized in power age. To address the restrictions utilities are putting forth impressive motivating forces to the client to introduce RES for power age. Throughout the years, the Solar oriented Photo Voltaic has one of the toughest competitors among available RES. Power created through Solar powered Photo Voltaic exhibit can be sustained straightforwardly to the network (lattice intelligent mode) or utilized to satisfy the power requirements of the off-framework loads (independent system). The current paper deals the issue of light-based Photo Voltaic frameworks working in independent mode to give capacity to household stacks in areas whereas the solar isn't accessible. Because of the less power absorbed by the solar we need a battery backup for the continuity of the power supply, so here we use the battery as a backup equipment.

Revised Manuscript Received on January 05, 2020.

* Correspondence Author

K .Priyanka*, Department of Electrical Engineering, VNR VJIET, Hyderabad, India, Email: priyankakandregula@gmail.com

Dr. J.Bhavani, Department of Electrical Engineering, VNR VJIET, Hyderabad, India, Email: bhavani_j@vnrvjiet.in

T. Nireeskhana Department of Electrical Engineering, VNR VJIET, Hyderabad, India, Email: nireekshana_t@vnrvjiet.in
For the off-grid systems are normally designed for lower applications range which varies from 250VA to 1000VA.The output of the solar system we see $12 \mathrm{~V}, 17 \mathrm{~V}$ and $36 \mathrm{~V}$ from the market. The battery range generally we choose for standalone system is $12 \mathrm{~V}$ to $48 \mathrm{~V}$ (here we use for the low power applications) but the standard voltage for Indian applications are $230 \mathrm{~V}$. The maximum voltage after the boost converter should be maintain at least $360 \mathrm{~V}$ to $400 \mathrm{~V}$ in order to satisfy the load requirement. Hence the design of the converter that should maintain the voltage gain, the voltage gain that should be intermediate to the battery backup and the dc-dc converter

Where the designed voltage gain should be around 9 to 12 , in order to run the system with three dc to dc converters we need this much high voltage gain. While this process we can observe the decrease in the output efficiency and the system reliability of the off grid loads with several power electronic converters. In another hand we can increase the voltage level by increasing the panel rating or the battery rating, but this will decrease the level of the voltage gain which is required for the dc to dc converter. Meanwhile, it may increase the system cost and installation issues and safety issues. Moreover, while increasing the rating of Photo Voltaic system to increase the voltage level the Photo Voltaic module they should be connected in series which increase the maximum number of the solar rays from the solar on the panel under non uniform isolation levels. For minimizing the issue, we should write difficult or long method of the Maximum Power Point algorithm or we might add the circuit for the system. In other hand we can increase the battery voltage by connecting in series but while connecting in series the price of the system and installation (space required of the equipment) complications we can see. Hence the number of switches is required is six and four for the converter where number of the switches are to be required for the dc to ac converter but in high frequency transformers needs large size and costly to install and there is reduce in the efficiency.

To achieve the disadvantages of the above methods a new boost inverter is needed where it can maintain the voltage gain which is required to dc side converter. the present topologies for the inverter which are used as a boost mode there are some draw backs of having the more voltage stress which is across the dc link Vdc capacitor , larger rating of the passive elements, there is complex in controlling and even we can see the high input of the ripple current. Above all disadvantages we can overcome with the new topologies of the novel boost type converter are proposed in this paper. 
where it operates in the buck mode and boost mode which is integrated to the full bridge inverter. The control strategy was explained in section 3 . The simulation and the results of the standalone system is explained in the section 4 .

\section{PRINCIPLE OF OPERATION}

In the below circuit diagram, the buck and boost converter are added to a full bridge inverter. Where the dotted lines indicate the buck boost operation having with the input voltage Vs and the output voltage denotes with Vo. where the switches are four T1, T2, T3 and T4 where Lf and Cf are the filters which are given to the resistive load. For each half cycle of operation two switches should be on and two switches should be in off state. Filters are used to reduce the harmonics .

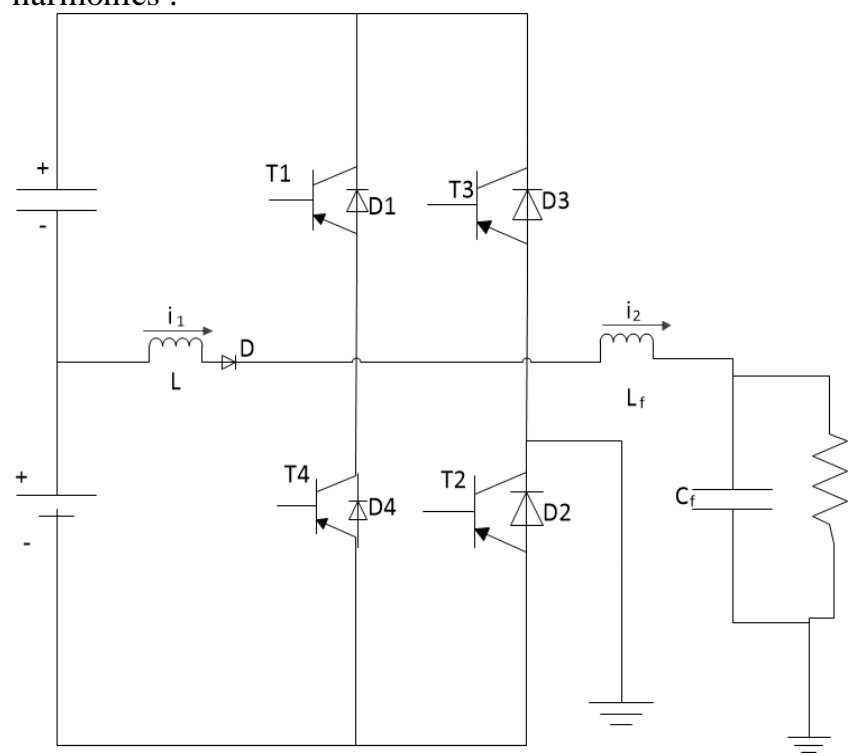

Fig1: schematic diagram of buck boost integrated to full bridge inverter

\section{WORKING PRINCIPLE OF INVERTER}

In system mainly operates in two modes. where in the mode 1 the switches $\mathrm{T} 1$ and $\mathrm{T} 2$ are in on state where the current flows through inductor $\mathrm{L}, \mathrm{i}(0)$ is greater than the current through Lf i2(0). Where T2 starts conducting the capacitor starts charging till i1 equals to i2. subsequently $\mathrm{c}$ gets discharge, where the energy stored in inductor is supplied to the load.

In mode 2 the switches T3 and T4 are in on state the power flows through inductor $\mathrm{L}$ and the Capacitor $\mathrm{C}$ and the switch T3 and Lf and the load where the $\mathrm{c}$ gets charging and subsequently c gets discharge the supplies power to the load.

\section{SCHEMATIC DIAGRAM OF BUCK BOOST INTYEGRATED WITH FULL BRIDGE STANDALONE SYSTEM}

As the maximum power is obtained by the solar panel is given the boost converter. Where for example 64 solar cells are connected in order to get the 32 volts as output, as per requirement we will connect the solar cells. To increase the voltage we will be using the boost converter as per the principle the voltage increases the twice than the input here maximum voltage we obtain is $\mathrm{Vdc}+\mathrm{Vc}$, but in order to maintain the voltage gain we have to use another boost converter but using to many converter the size and losses will be increasing in order to reduce the losses we have integrate the buck boost converter to the full bridge inverter as the number of the switches will be reduce, because normally we will be having six switches here two switches are reduced,so that we can minimize the switching losses and conduction losses.

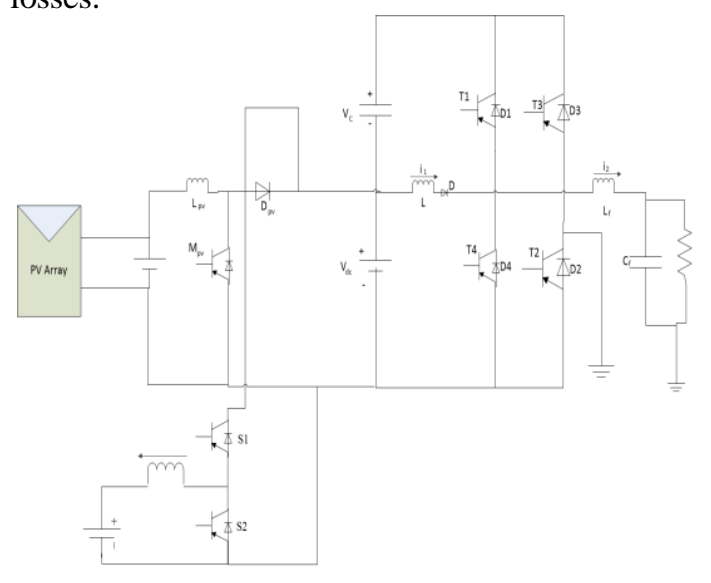

Fig2: Schematic Diagram of Standalone System

Where the output of the boost converter is given to the buck boost integrated with full bridge inverter as the voltage is increased, where the inverter converts dc to act as per the output we will be getting $230 \mathrm{v}$ ac output, but we will be getting some ripples whenever we using a power electronic component we will be having some ripples in order to minimize the ripples we are using the filters, here an lc filter is using so that the ripples are controlled maximum and the smooth output is obtained.

As per the stand-alone system cannot supply continuous supply throughout the day. In order to get the continuous power supply, we are using a bidirectional dc to dc converter. A bidirectional converter is a converter which supply the power and observers the supply in both directions. Here we are using non isolated bidirectional dc-dc converter. Two switches will be, here the battery is connected to the another end of the bidirectional system , the supply or the duty cycle was taken from the output of the solar Maximum Power Point and given to the controller logic so that if maximum power is obtained means the battery will be getting charge if obtained power is not sufficient then the battery will be discharging and the power is supplied to the load .

The control operation of the system will be depending on the solar panel output. Where the dc side the control logic is applicable to control the capacitor voltage $\mathrm{Vc}$ to get the desire values the mode 1 indicates the Maximum Power Point is on where the mode 0 indicates the Maximum Power Point is in off mode trough this the signals are generated for a standalone system where we can explain in four ways like Maximum Power Point mode ,non-Maximum Power Point mode, battery mode. Where in the Maximum Power Point mode the obtained max power from solar is Pmpp.

$$
\begin{aligned}
& P b a t=P m p p-P l \\
& \mathrm{P}_{\mathrm{bat}}=\text { battery power } \\
& \mathrm{P}_{1}=\text { sum of the load } \\
& \text { demand }
\end{aligned}
$$


When a system is operating in the Maximum Power Point mode the battery should be charged Pmpp $>\mathrm{Pl}$, battery should discharge for Pmpp $<\mathrm{Pl}$. In order to maintain safety, we must operate in safe modes, so we take some limit values. Let us assume some limit values according to output for boost converter so that beyond the limit value the system should not work. Assume IBmax IBmin and IBref for the current in the battery side.

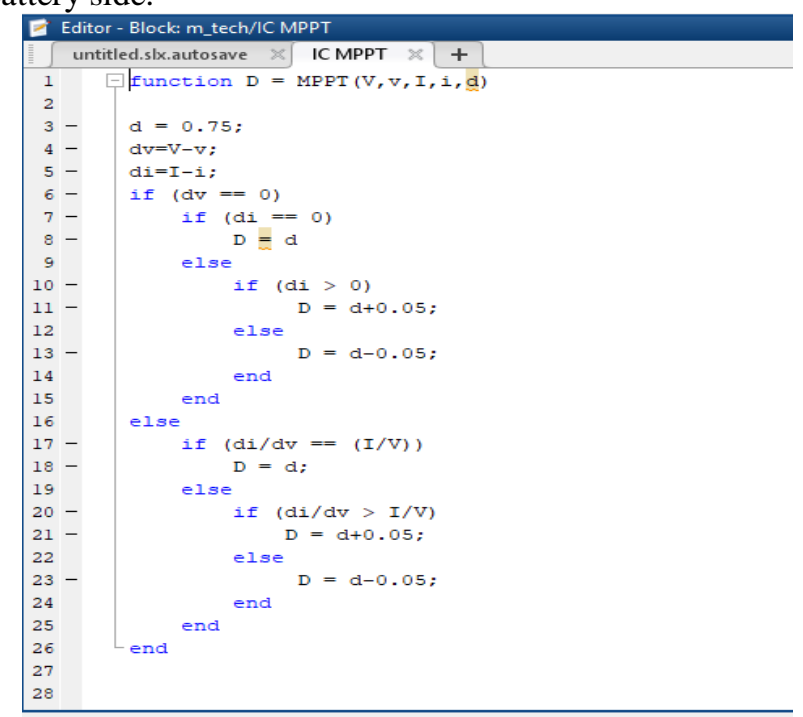

Fig3: Maximum Power Point Algorithm for a standalone system

When the control system operates at Maximum Power Point mode With a current the battery gets charged i.e. with surplus power Pmpp-Pl. where the surplus amount exceeds the limit value of the battery maximum current will also exceeds. In this mode the power of the battery should be limited otherwise the battery may suffer from overcharging. Therefore, we should take reference value of the battery current compared to the maximum battery current. Anyhow once the battery power reaches to the maximum it cannot work in the Maximum Power Point mode and there is no elements that can observe the excess surplus amount of power that is Pmax-Pl-Pt. automatically the system transfer from Maximum Power Point mode to Non Maximum Power Point mode ,this mode will appear only once the IBref value reaches to the maximum battery current. Then it indicates Maximum Power Point mode $=0$ and Non-Maximum Power Point mode $=1$.

Where in the non-Maximum Power Point mode the battery convert will be controlled by maximum battery current with respect to the maximum power of the battery. In the other hand the output of the Photo Voltaic side the DC link should be maintained with the help of the Maximum Power Point algorithm. Hence the Maximum Power Point mode is in OFF state the Photo Voltaic array works other than the Maximum Power Point mode, then the power taken from Solar array is equal to the Pmax $+\mathrm{Pl}$. As the load demand changes the output of the Solar array also changes by the same amount in order to maintain the steady state condition as the battery absorbs Pmax whenever the power demand increase beyond the point the Photo Voltaic power decreases too short for supply the increment in the demand the capacitor $\mathrm{C}$ and $\mathrm{Cdc}$ will start discharging to meet the load demand of the system. In result the total amount of the dc link voltage will be falling, this will happen until the battery changes in charging mode of operation, if dc link voltage decreases below the reference value it is difficult to control the converter to meet the desired voltage value.

\section{SIMULATION}

For the standalone system has been simulated various parameter is taken in simulation study, here we connected 60 solar cells. Where in each module it contains 12 cells and each module are connected in parallel and the voltage across $\mathrm{Vc}+\mathrm{Vdc}=400 \mathrm{v}$, Output of the solar panel is $13 \mathrm{v}$ and expected output to the load is $230 \mathrm{v}$, the sort circuit current is Isc $=4.75 \mathrm{amp}$. Where the perturb and observation algorithm is used for the Maximum Power Point. Values used for simulation Solar inductor and capacitor are $2 * 10-3 \mathrm{H}$ and $2 * 10-9 \mathrm{~F}$, battery side inductor is $2 * 10-3 \mathrm{H}$, inverter inductor is $5 * 10-3 \mathrm{H}$ and capacitor $\mathrm{Cdc}$ is $3 * 10-9 \mathrm{~F}$, filter inductor and capacitor are $2 * 10-3 \mathrm{H}, 5 * 10-6 \mathrm{~F}$.
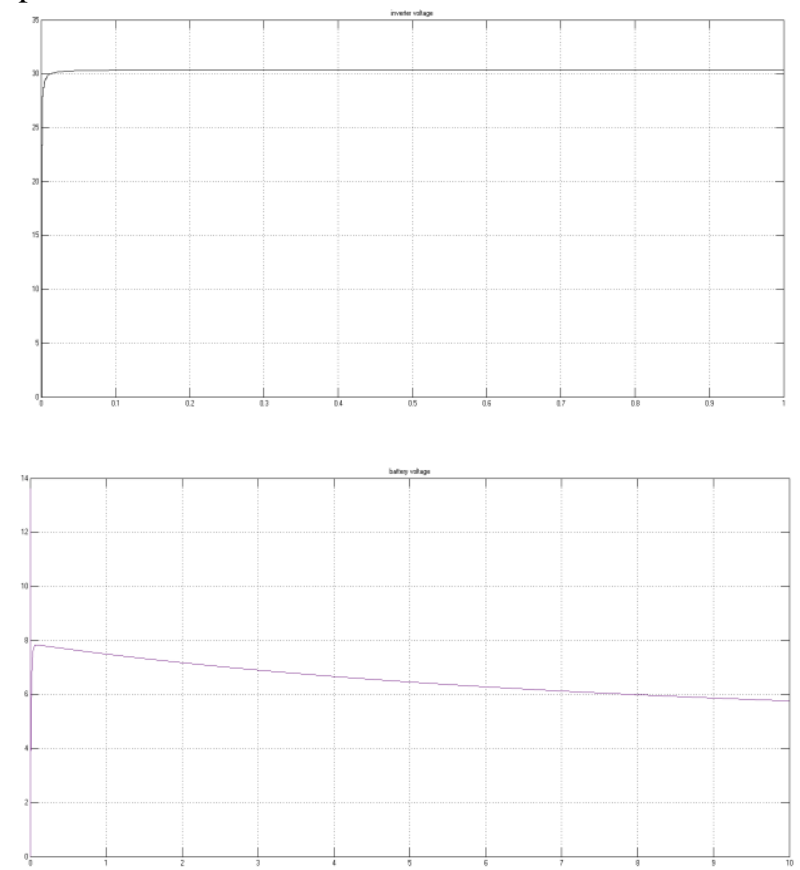

Fig 4: The output power of Solar and the Battery

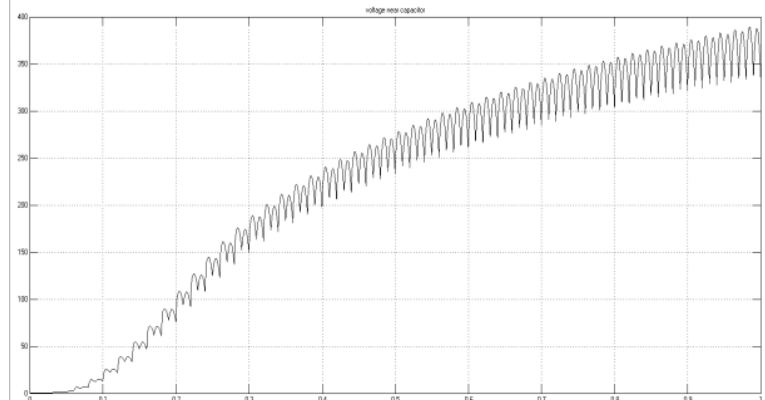

Fig 5: The output voltage of Capacitor $\left(V_{c}\right)$ and dc link voltage 


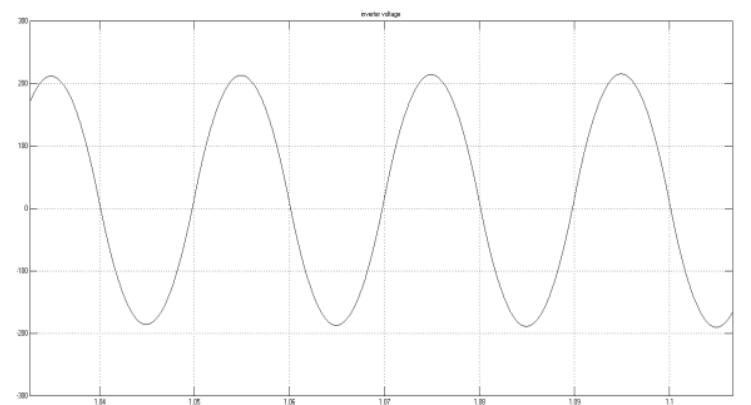

Fig 6: Inverter output voltage

\section{CONCLUSION}

A novel converter which works as both types of buck converter and boost converter according to the output of solar, i.e. a combination working of the buck and boost converter which is added to full bridge inverter. For standalone system this type of applications are very useful. Hence the in stages of power conversion we can reduce so that switches will be reduced hence the switching losses will be less. With bi-directional DC-DC converter we maintain uninterruptable power supply to the system. As a result, the efficiency and reliability were maintained, and safety is also taken in consideration. By simulation studies we can observe the efficiency of the system.

\section{REFERENCES}

1. Dipankar Debnath, Kishore Chatterjee. "A buckboost integrated full bridge inverter for solar photovoltaic based standalone system", 2013 IEEE 39th Photovoltaic Specialists Conference.

2. "PV Output smoothing with energy storage" by A.Ellis. J.Hawkins, S.Willard and B.Arrellano, 38th IEEE photovoltaic specialists conference 2012

3. H.Mastuo and F.Kurokawa "New solar cell power supply system using a boost type bidirectional dc-dc converter" IEEE Trans on Indus Elect

4. J.H.Wohlegemuth and S.R.Kurtz "How can we make PV modules safer? " 38th IEEE PV specialists conference 2012.

5. K.Kobavashi, I Takanoand Ysawada, "A Study on a 2 stage MPPT control of a PV system under partially shaded insolation conditions", IEEE power Eng. Soc Gen meeting 2013

6. J.T.Staurth, M.D.Seeman and K.Kesawani ,'Resonant switched capacitor converters for sub-module distributed PV power management" IEEE Trams on Power Elect 2013

7. T.Shimzu, M.Hirakata, T.Kamezawa and H.Watanabe "Generation control circuit for PV modules", IEEE Trans on power Elect 2001

8. H. Wang and D.Zhang "The stand- alone PV generation system with parallel battery charger", ICECE 2010

9. C.Zhao, S.D. Round and J.W. Kolar "An isolated there port bidirectional dc dc converter with decoupled power flow management" IEEE trans on power elect 2008

10. R.O.Caceres and I. Barbi "A boost Dc Ac converter analysis design and experimentation", IEEE transactions on power electronics 1999

11. P.Sharma, P.K.Peter and V.Agarwal,"Exact maximum power point tracking of partially shaped PV strings based on current equalization concept", 38th IEEE pv specialists conference 2012

12. L.Shengyong, Z.Xing, G.Haibin and X.Jun,"Multiport dc-dc converter for standalone pv lighting system with battery storage" ICECE 2010

\section{AUTHORS PROFILE}

Priyanka Kandregula student at EEE department pursuing masters(Mtech $2^{\text {nd }}$ year) at VNRVJIET, Hydrebad in Power Electronics and interested in research work smart energy systems and Hybrid energy storage applications.

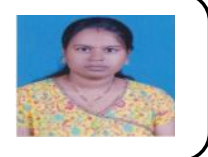

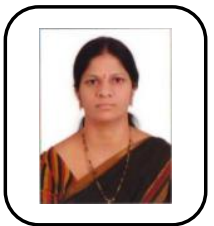

Dr. J.Bhavani Associate professor at EEE department, VNRVJIET ,Hyderabad .she was Graduated from SV University affiliated college in 2000 , post Graduation in power Electronics from JNTUH in 2005 and has received doctorate in 2015 from JNTUH, Hyderabad. Published 16 international journals and 10 international conferences . research area is PWM schemes, DC-DC Converters and Renewable energy systems . Received best paper award and best young women scientist award

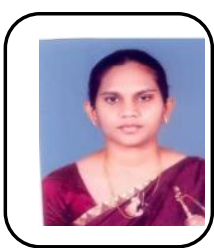

Dr. T. Nireekshana Associate professor at EEE department, VNRVJIET ,Hyderabad . Graduated from JNTUK affiliated college in 2000 , post graduation in power systems from JNTUK in 2005 and has received doctorate in 2015 from JNTUK, Hyderabad. Published 39 international and national journals . Research area is received deregulation and optimal power flow and received award best young Engineering scientist 